$\begin{array}{r}\text { Bartın Üniversitesi } \\ \text { Eğitim Fakültesi Dergisi }\end{array}$
Cilt 6, Sayı 3, s. 1093-1104, Ekim 2017
BARTIN - TÜRKIYE $\begin{aligned} & \text { Bartin University } \\ & \text { Journal of Faculty of Education } \\ & \text { Volume 6, Issue 3, p. 1093-1104, October } 2017 \\ & \text { BARTIN - TURKEY }\end{aligned}$

Doi: $10.14686 /$ buefad.332383

\title{
Akreditasyon Algısı (AA) Ölçeğinin Geliştirilmesi: Geçerlik ve Güvenirlik Çalışması
}

Çetin SEMERCI, Prof. Dr, Bartın Üniversitesi, Eğitim Fakültesi, ctnsem @gmail.com,

ORCID: http://orcid.org/0000 000263375876

Öz: Akreditasyon, yetki, yeterlik ve güvenirliğin onaylandığı sertifikalı bir kalite güvence sürecidir. Araştırmanın amacı, akreditasyon algısı (AA) ölçeğinin geliştirilmesidir. Araştırmada tarama modeli kullanılmıştır. Taslak ölçek, geliştirilmek üzere Türkiye'de Batı Karadeniz bölgesindeki bir üniversitede, 738 öğrenci ve öğretim elemanına uygulanmıştır. Faktör analizi sonuçlarına göre, AA ölçeğinin KMO değeri 0.964, Bartlett testi değeri 6.045E3'dir ( $S d=253, p=0.000$ ). Ölçek, varyansın \% 43.357'sini karşılamaktadır. AA ölçeği için yapılan analiz sonuçlarında, faktör yüklerinin 0.538-0.692 arasında değiştiği görülmektedir. Ölçek tek boyutlu ve çok boyutlu olarak kullanılabilir. Ölçeğin alt temaları, kalite güvencesi ve kalite değerlendirmesidir. Ölçek, 17 maddeden oluşmuştur. AA ölçeği, "Tamamen katılıyorum (5), Çoğunlukla katılıyorum (4), Kısmen katılıyorum (3), Az katılıyorum, (2), Hiç katılmıyorum (1)" şeklinde derecelendirilmiştir. Ölçeğin, iki yarı puanları arasındaki korelasyon katsayısı 0.831 bulunmuştur. AA ölçeğinin Cronbach Alpha katsayısı 0.901 'dir. Ayrıca, AA ölçeğinin AMOS programı ile doğrulayıcı faktör analizi yapılmıştır (Kay kare=238.872, $\mathrm{Sd}=117, \mathrm{X}^{2} / \mathrm{Sd}=2.042, \mathrm{GFI}=0.963, \mathrm{CFI}=0.969, \mathrm{RMSEA}=0.038$ ). AA ölçeği geçerlik ve güvenirlik sonuçlarına göre, üniversite öğrencilerine ve öğretim elemanlarına uygulanabilir.

Anahtar Kelimeler: akreditasyon algısı, geçerlik, güvenirlik, ölçek geliştirme

\section{The Development of Accreditation Perception (AP) Scale: Validity and Reliability Study}

\begin{abstract}
Accreditation is a quality assurance process by which authority, competency and credibility are certified. This research aims to develop an Accreditation Perception (AP) scale. The survey method was used in this study. Draft scale was applied to 738 students and faculty staff. It was applied in a university in the western black sea region in Turkey (738). According to the factor analysis results, $\mathrm{KMO}$ value of the AP scale is 0.964 and the Bartlett test value is $6.045 \mathrm{E} 3$ ( $\mathrm{Df}=253, \mathrm{p}=0.000$ ). It is shown that variance of the scale is $43.357 \%$. Factor loadings range from 0.538 to 0.692 . The scale can be used as one-dimensional and a multi-dimensional. Sub-themes (Sub-dimensions) of the scale are quality assurance and quality assessment. There are a total of 17 items in the scale. Evaluation of the scale was like this: "Totally agree (5), Mostly agree (4), Partially agree (3), Slightly agree (2), Disagree (1)". In the scale, it was figured out that the correlation between parallel two half scores was 0.831 . The Cronbach Alpha coefficient of the AP scale was 0.901 . The validity and reliability analysis of the scale and the confirmatory factor analysis with AMOS program was performed (Chi-square=238.872, Df=117, $\mathrm{X}^{2} / \mathrm{Sd}=2.042, \mathrm{GFI}=0.963, \mathrm{CFI}=0.969, \mathrm{RMSEA}=0.038$ ). According to these results, the scale can be applied to students and faculty staff.
\end{abstract}

Key Words: accreditation perception, validity, reliability, scale development 


\section{GiRiş}

Akreditasyon, Latince kökenli Fransızca bir kavram (Doğan, 1999, 511) olmasına rağmen, on yıl öncesine kadar sadece Amerikalılara özgü bir yöntem olarak bilinirdi (Fraser, 1994 akt. Herdman, 2010, 3). Ancak, günümüzde tüm dünyaya yayıldığı söylenebilir.

Akreditasyon, Avrupa Üniversiteler Birliği tarafından "kamuya hizmet veren bir kurum veya programın kalitede asgari standartları tutturması" şeklinde açıklanmış ve kalite güvencesinin doğal sonuçlarından biri olduğu vurgulanmış (Campbell and Rozsnyai, 2002 akt. Herdman, 2010, 3), Türkiye'de, Yükseköğretim Kalite Güvencesi Yönetmeliği'nde “Bir dış değerlendirici kurum tarafından belirli bir alanda önceden belirlenmiş akademik ve alana özgü standartların bir yükseköğretim programı tarafından karşılanıp karşılanmadığını ölçen değerlendirme ve dış kalite güvence sürecidir" (YÖK, 2015; Ayvaz, Kuşakçı ve Borat, 2016, 6) şeklinde açıklanmıştır. Akreditasyonun, öz düzenlemenin bir biçimi olarak da kabul edildiği (Young, 1979 akt. Bakioğlu ve Baltacı, 2017, 37) varsayılırsa, akredite etmenin amacı, kurumlarda ürün kalitesini artırarak orada çalışanların motivasyonlarını da olumlu yönde artırmak (Doğan, 1999, 511) gerekir.

Akreditasyon, kurum ve programların markalaşmasında ve sürdürülebilir olmasında katkı sağlamaktadır. Chernay (1990), akredite olan kurumlar ya da programlar eğitimde uygun hedeflerini açıkça tanımladığından, akreditasyonun toplumsal eğitimin, genel kamu veya diğer kuruluşların garantisi olduğunu iddia eder. Akreditasyon aynı zamanda kurumların hangi koşullar altında amacına ulaşılabileceğinin belirlenmesini, bu koşulların sürdürülebilmesi için gerekli düzenlemelerin yapılmasını sağlar (Akt. Herdman, 2010, 3).

Akreditasyon, diğer taraftan yetki, yeterlik ve güvenirliğin onaylandığı sertifikalı bir kalite güvence sistemi ve sürecidir (Herdman, 2010, 3). Bu açıdan akreditasyon ve kalite güvencesi iç içe girmiş kavramlardır. Kalite Güvencesi, "bir yükseköğretim kurumunun veya programının iç ve dış kalite standartları ile uyumlu kalite ve performans süreçlerini tam olarak yerine getirdiğine dair güvence sağlayabilmek için yapılan tüm planlı ve sistemli işlemlerdir" (YÖK, 2015; Ayvaz, Kuşakçı ve Borat, 2016, 5) şeklinde açıklanabilir. Akreditasyon aynı zamanda kalite değerlendirmeyi kapsayan bir modeldir. YÖK'e (2015) göre, kalite değerlendirme, bir yükseköğretim kurumunun/bir bölümün/bir programın eğitim-öğretim, araştırma ve idarî hizmetlerinin kalitesinin ölçülüp uygunluğuna karar verilmesidir.

Türkiye'deki üniversitelerde akreditasyonun başarısında öğretim elemanları ile öğrencilerin algı ve düşünceleri büyük önem taşımaktadır. Bu anlamda, yapılan çalışmalarda öğretim elemanlarının akreditasyon algılarının çok yüksek olmadığı görülmektedir. Öğretim elemanlarının sadece beşte ikisi (2/5) akreditasyon sürecinin fakültelerde kaliteyi artıracağına inanmakta ve üçte birinin de akredite edilme süreceğine hazır oldukları görülmektedir (Erkuş, 2003, 3). Akreditasyon kavramının yeterince benimsenmemesinin (Ünal, Semerci ve Semerci 2017; Erkuş, 2003, 3) bir sebebi olarak, bu kavramın yeterince bilinmemesinden kaynaklandığı düşünülebilir. Bu çalışmayla akreditasyon algılarının ölçülmesine katkıda bulunmak için bir ölçme aracı geliştirilmeye çalışılmıştır.

\subsection{Araştırmanın Amacı}

Araştırmanın amacı, akreditasyon algısı (AA) ölçeğinin geçerlik ve güvenirlik çalışmalarıyla geliştirilmesidir. Bu amaçla, geçerlik ve güvenirlik çerçevesinde madde havuzu, uzman görüşü, uygulama, faktör analizi, güvenirlik katsayıları ve doğrulayıcı faktör analizi çalışmalarına yer verilmiştir. 


\section{YÖNTEM}

Ölçek geliştirmeye ilişkin bu araştırmada tarama modeli kullanılmıştır. Bu model çerçevesinde, olay ve durumların mevcut incelemesi yapılır (Kaptan, 1998, 59; Büyüköztürk vd., 2009, 16-17; Karasar, 1995, 77; Sönmez ve Alacapınar, 2011). "Akreditasyon algısı" ölçeği 81 maddelik bir havuzdan uzman görüşüyle 75 maddeye indirilmiş ve 738 örneklem grubunda tek ve çok boyutlu olarak belirlenmiştir.

\subsection{Araştırma Örneklemi}

Taslak ölçek, geliştirilmek üzere 709 öğrenci ve 29 öğretim elemanına uygulanmıştır. Uygulama, Türkiye'de Batı Karadeniz bölgesindeki bir üniversitede yapılmış olup Tablo 1'de çalışma örnekleminin dağııımı görülmektedir.

Tablo 1.

Çalışma örnekleminin dağılımı

\begin{tabular}{lrr}
\hline Örneklem & N & \% \\
\hline Beden Eğitimi ve Spor yüksekokulu & 38 & 5.1 \\
Edebiyat Fakültesi & 52 & 7.0 \\
Fen Fakültesi & 35 & 4.7 \\
İktisadi ve İdari Bilimler Fakültesi & 15 & 2.0 \\
İslami İlimler Fakültesi & 14 & 1.9 \\
Sağlık Bilimleri Fakültesi & 8 & 1.1 \\
Eğitim Fakültesi & 547 & 74.1 \\
Öğretim Elemanları & 29 & 3.9 \\
\hline TOPLAM & 738 & 100.0 \\
\hline
\end{tabular}

Çalışma örneklemini, pedagojik formasyon eğitimi almaya gelen öğrencilerle eğitim fakültesi öğrencileri ve öğretim elemanları oluşturmuştur. Pedagojik formasyon öğrencilerinin \%25'i üniversite dışından gelen öğrenciler olduğu düşünülürse farklı üniversitelerden gelen öğrencilerin de çalışmaya katıldı̆̆ı söylenebilir. En yüksek katılım eğitim fakültesi öğrencilerinden (\%74.1) iken, en düşük katılım sağlık bilimleri fakültesi öğrencilerinden (\%1.1) olmuştur. Öğretim elemanlarının katılım oranı \%3.9'dur. Bu çerçevede toplam 738 kişiye ulaşılmıştır. Akreditasyon ölçeğinin geliştirilme aşamaları aşağıda verilmiştir:

\section{AKREDITASYON ÖLÇEĞiNIN GELIŞTIRILMESi} verilmiştir:

Akreditasyon ölçeği geliştirilirken altı (6) aşamadan geçmiş olup bunlar aşağıda

\subsection{Alanyazın ve Madde Havuzu}

Akreditasyon Algısı ölçeği, alanyazın taraması ve araştırmaların incelenmesi sonucunda 81 maddeden oluşmuş ve uzman görüşleri doğrultusunda, 6 maddesi çıkarılarak 75 madde olarak havuza konulmuştur (Tablo 2). Ölçeğin, "Tamamen katılıyorum (5), Çoğunlukla katılıyorum (4), Kısmen katılıyorum (3), Az katılıyorum(2), Hiç katılmıyorum (1)" şeklinde derecelendirmesi yapılmıştır. 
Tablo 2.

Akreditasyon Algısı Ölçeğinin Madde Havuzu

1. Akreditasyon ve kalite, büyümenin temel köprüsüdür.

2. Akreditasyon, minimum standartlarla değerlendirmedir.

3. Akreditasyon ve kalite, saygınlıktır, imajı yükseltir.

4. Akreditasyon, ulusal ve uluslararası tanınmayı kolaylaştırır.

5. Akreditasyon, bir eğitim programının kendin gerçekleştirmesidir.

6. Akreditasyon, varolmanın tescillenmesidir.

7. Akreditasyon, belge veya rapor değildir, kaliteye kalite katma çabasıdır.

8. Akreditasyon, mevcut kaliteyi rehberler aracılığıyla belirlemek ve eksikliklerin tamamlanmasını sağlamaktır.

9. Akreditasyon, öğretim elemanından donanıma kadar eksikliklerin giderilmesidir.

10. Akreditasyon, bir programı yaşatma güvencesidir.

11. Akredite olan bir programla olmayan programa bakış açıları farklıdır.

12. Akreditasyonda erken yola çıkan hızlı yol alır.

13. Akreditasyon ve kalite sürecinde, yöneticilerin kararlı olmas gerekir.

14. Akreditasyon, programların geleceğinin güvence altına alınmasıdır.

15. Akreditasyondan korkmak acizliktir

16. Akreditasyondan korkanlar, ölçülüp değerlendirmeden korkan kişilerdir.

17. Akreditasyon, tercih edilen bir programın kalite güvencesidir.

18. Akreditasyon, programların iş yapabilir becerisinin kanıtıdır.

19. Akreditasyonun başlangıcı, bir işin yapılabileceğine olan inançtır

20. Akreditasyon, programların temelinin sağlamlık derecesidir.

21. Akreditasyon, sağlam temelin üzerinde kalitenin yükseltilmesidir

22. Akreditasyon, en iyi kaliteye doğru itici bir güçtür.

23. Akreditasyon, programların güvenilir ve inanılır olma halidir.

24. Akreditasyon, bir cesaret göstergesidir

25. Akreditasyonda kaybetmek yoktur, hep kazan kazan vardır.

26. Akreditasyon, bir programda kalitenin güvenlik kamerasıdır.

27. Akreditasyon, uzman dış değerlendirmecilerin programla ilgili kara vermesidir.

28. Akreditasyon, program geliştirme uzmanlarının önemli olduğunu gösterir.

29. Akreditasyon, ölçme ve değerlendirmedir.

30. Akreditasyon, sürdürülebilir bir kalite göstergesidir.

31. Akreditasyon, öğrencisinden çaycısına, güvenliğinden kütüphanesine kadar işbirliğiyle çalışmanın bir sonucunun karşılığıdır.

32. Akreditasyon, sınav sorularının ve ders kazanım/içeriklerin gösterildiği bir belirtke tablosu (Ölçme matrisi) gibidir.

33. Akreditasyon, çoklu testlerle (sınavlarla) yapılan bir ölçme gibidir.

34. Akreditasyon, bir dersten geçer not alma gibidir.

35. Akreditasyon, programlarda temel standartların sağlanmasıdır.

36. Akreditasyon, kalite çizgisinin tabanıdır.

37. Akreditasyon, dost, düşman herkesin senin yaptığın işe güvenmesidir

38. Akreditasyon, işini iyi yapanların onure edilmesidir.

39. Akreditasyon, ard niyetli program hazırlayıcıların ayıklanmasıdır

40. Akreditasyon, olmazsa olmaz içeriklerin derste öğretilmesin sağlamaktır.
41. Akreditasyon, programlarda nicel ve nitel tüm eksikliklerin belirlenmesi ve giderilmesidir.

42. Akreditasyon, hem programın hem de öğrencilerin yeterli olduğunu gösterir.

43. Akreditasyon, disiplinli çalışmayı gerektirir.

44. Akreditasyon, bir formattır, uyulması gerekir.

45. Akreditasyon, bir derse ilişkin en uygun öğretim yöntem ve tekniklerin kullanılmasını gerektirir.

46. Akreditasyon, bir kalite kültürüdür

47. Akreditasyon, standart bir program prosedürüdür.

48. Akredite olmayan kurumlar sıradan olmaya mahkumdur.

49. Akredite olan kurum/programlar öncü olmaya adaydır.

50. Akreditasyon, sizin kendinizi övmeniz değil, başkalarının sizi övmesidir.

51. Akreditasyon, algı, imaj ve kaliteyi olumlu yönde etkileyen bir faktördür.

52. Akreditasyon, öğrencilerin eğitim yaşantılarını olumlu yönde değiştirmeye katkıda bulunur.

53. Akreditasyon, programa daha kaliteli öğrencilerin gelmesini sağlar.

54. Akreditasyon, programa alanında tanınmış akademisyenlerin istihdam edilmesi sağlar.

55. Akreditasyon, mezun öğrencilerin daha iyi iş fırsatları elde etmesine imkan sağlar.

56. Akreditasyon, personele kişisel gelişim, farkındalık ve vizyon oluşturabilir.

57. Akreditasyon, eğitim kalitesinin bir göstergesidir.

58. Akreditasyon, kalite olarak iç süreçleri iyileştirir.

59. Akreditasyon, yaşam boyu kalite mücadelesi için atılan bir adımdır.

60. Akreditasyon, standartların karşılanmasını sağlayan bir araç olmasının yanısıra gelişimi de destekler.

61. Akreditasyon, öğrencilerin kaliteli öğretim elemanları tarafından eğitilmesidir.

62. Akreditasyon, eğitim-öğretimin niteliğinin güvence altına alınmasıdır.

63. Akreditasyon, doğrudan yaptırımları olan bir denetim sistem değildir.

64. Akreditasyon ve kalite için tüm paydaşların hesap verebilir olması gerekir.

65. Akreditasyon, topluma öğretimde kalite temini sunan organize bir yöntemdir.

66. Akreditasyon, öğretim kalitesine olumlu yönde katkı sağlayan başarılı bir girişimdir.

67. Akreditasyon, kalite yönetiminin bir alt boyutu olarak değerlendirilebilir.

68. Akreditasyon, kaliteyi değerlendirmek için kullanılan bir araç ve yöntemdir.

69. Akreditasyon ve kalite ilişkisinde kurum misyonu açık ve net olmalıdır.

70. Akreditasyonda misyon, programın ruhu, kalbi ve aklıdır.

71. Akreditasyon, minimum kalite standartlarının karşılanmasıdır.

72. Akreditasyon süreci, kaliteyi teminat altına alır.

73. Eğitimde akreditasyon, bir kalite kontrol ve temin sürecidir

74. Akreditasyondan kaynaklanan rekabetçe ruh, kalitenin iyileşmesine katkıda bulunur.

75. Akreditasyonun olmazsa olmaz şartlarından biri şeffaf olmaktır

\subsection{Uzman Görüşleri ve Uygulama}

AA ölçeği uzman görüşü alınmak üzere iki farklı üniversitenin Eğitim Fakültelerinde görev yapan ve akreditasyon konularıyla ilgili iki (2) yardımcı doçent ve bir (1) profesöre verilmiştir. Ayrıca, sekiz (8) yüksek lisans ve iki (2) doktora öğrencisine, ilgili maddelerin anlaşılırlığı hususunda görüş sorulmuştur. Uzman ve öğrenci görüşleri doğrultusunda maddeler 
üzerinde küçük ifade düzeltmeleriyle uzlaşma sağlanmıştır. Taslak ölçek, 75 maddeden oluşmaktadır (Tablo 2). Uzman görüşleri doğrultusunda belirlenen bu maddeler, 738 öğrenci ve öğretim elemanlarına uygulanmış ve veriler işleme konulmuştur. Ölçeğin faktör yükleri ve madde toplam korelasyonları Tablo 3'te verilmiştir.

\subsection{Açımlayıcı Faktör Analizi ve Madde Toplam Korelasyonları}

Havuzda oluşturulan 75 madde için açımlayıcı faktör analizi yapılmıştır. Faktör analizi, "Birbiriyle ilişkili $p$ tane değişkeni bir araya getirerek az sayıda ilişkisiz ve kavramsal olarak anlamlı yeni boyutlar bulmayı, keşfetmeyi hedefleyen çok değişkenli bir istatistiktir" (Büyüköztürk, 2002, 117). Çalışmada, faktör yükleri 0.50'nin altında olan maddeler ölçeğe alınmamıştır. Ölçeğin faktör yükleri Tablo 3 'te sunulmuştur. Ölçek tek boyutlu ve çok boyutlu Tablo 3.

Akreditasyon Algısı Ölçeğinin faktör yükleri ve madde toplam korelasyonları

\begin{tabular}{|c|c|c|c|c|c|c|}
\hline 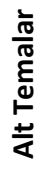 & 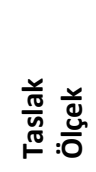 & 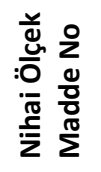 & Maddeler & 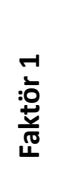 & 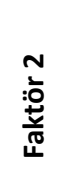 & 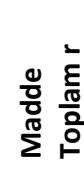 \\
\hline \multirow{7}{*}{ 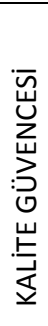 } & 4 & 1 & Akreditasyon, ulusal ve uluslararası tanınmayı kolaylaştırır. & .62 & & $.56^{*}$ \\
\hline & 5 & 2 & Akreditasyon, bir eğitim programının kendini gerçekleştirmesidir. & .69 & & $.61^{*}$ \\
\hline & 6 & 3 & Akreditasyon, varolmanın tescillenmesidir. & .66 & & $.59 *$ \\
\hline & 7 & 4 & $\begin{array}{l}\text { Akreditasyon, belge veya rapor değildir, kaliteye kalite katma } \\
\text { çabasıdır. }\end{array}$ & .59 & & $.62^{*}$ \\
\hline & 10 & 5 & Akreditasyon, bir programı yaşatma güvencesidir. & .59 & & $.55^{*}$ \\
\hline & 14 & 6 & Akreditasyon, programların geleceğinin güvence altına alınmasıdır. & .59 & & $.60^{*}$ \\
\hline & 17 & 7 & Akreditasyon, tercih edilen bir programın kalite güvencesidir. & .54 & & $.65^{*}$ \\
\hline \multirow{10}{*}{ 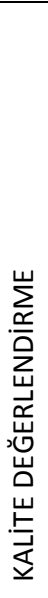 } & 30 & 8 & Akreditasyon, sürdürülebilir bir kalite göstergesidir. & & .54 & $.68^{*}$ \\
\hline & 36 & 9 & Akreditasyon, kalite çizgisinin tabanıdır. & & .57 & $.62^{*}$ \\
\hline & 46 & 10 & Akreditasyon, bir kalite kültürüdür. & & .57 & $.61^{*}$ \\
\hline & 51 & 11 & $\begin{array}{l}\text { Akreditasyon, algı, imaj ve kaliteyi olumlu yönde etkileyen bir } \\
\text { faktördür. }\end{array}$ & & .59 & $.65^{*}$ \\
\hline & 57 & 12 & Akreditasyon, eğitim kalitesinin bir göstergesidir. & & .63 & $.66^{*}$ \\
\hline & 59 & 13 & Akreditasyon, yaşam boyu kalite mücadelesi için atılan bir adımdır. & & .60 & $.64^{*}$ \\
\hline & 64 & 14 & $\begin{array}{l}\text { Akreditasyon ve kalite için tüm paydaşların hesap verebilir olması } \\
\text { gerekir. }\end{array}$ & & .61 & $.58^{*}$ \\
\hline & 66 & 15 & $\begin{array}{l}\text { Akreditasyon, öğretim kalitesine olumlu yönde katkı sağlayan } \\
\text { başarılı bir girişimdir. }\end{array}$ & & .65 & $.66^{*}$ \\
\hline & 67 & 16 & $\begin{array}{l}\text { Akreditasyon, kalite yönetiminin bir alt boyutu olarak } \\
\text { değerlendirilebilir. }\end{array}$ & & .56 & $.62^{*}$ \\
\hline & 68 & 17 & $\begin{array}{l}\text { Akreditasyon, kaliteyi değerlendirmek için kullanılan bir araç ve } \\
\text { yöntemdir. }\end{array}$ & & .68 & $.68^{*}$ \\
\hline
\end{tabular}

olarak kullanılabilir. Faktör yükleri 0.538-0.692 arasında değişmektedir. Faktör yükü, ölçek maddelerinin faktörlerle (temalarla) olan ilişkisini açıklayan bir katsayıdır. Akademik İstatistik'e (2017) göre, bir maddenin faktör yükü yüksekse, o maddenin söz konusu faktörle güçlü bir ilişkisi olduğu anlamına gelir. Faktör analizi sonucunda varyansın \% 43.357'sini karşıladığı söylenebilir. AA ölçeğinin KMO değeri 0.964, Bartlett testi değeri 6.045E3'dir ( $\mathrm{Sd}=253$, $p=0.000)$. AA Ölçeğinin madde toplam korelasyonları hesaplanmıştır. AA ölçeği için yapılan analizlerde, madde toplam korelasyonları 0.55-0.68 arasında değişmiştir (Tablo 3). Büyüköztürk (2002, 32), madde toplam korelasyonlarının 0.30 ve üzerinde olmasının yeterli olduğunu vurgulamaktadır. 


\subsection{Alt Temalar ve Aralarındaki Korelasyonlar}

Ölçeğin alt temaları, kalite güvencesi ve kalite değerlendirmedir. Kalite güvencesi 7 madde ve kalite değerlendirme 10 madde olmak üzere ölçekte toplam 17 madde yer almıştır. AA Ölçeğinin alt boyutlarının kendi aralarındaki korelasyon sonuçları incelendiğinde, kalite güvencesi ve kalite değerlendirme boyutları arasında 0.703 'lük bir ilişki bulunmuştur (Tablo 4).

Tablo 4.

Akreditasyon algısı ölçeğinin alt temalarının birbiriyle korelasyonları

Kalite Güvencesi

Kalite Değerlendirme

Kalite Güvencesi

1

$.703^{* *}$

Kalite Değerlendirme

$\mathrm{P}<0.01$

\subsection{Eşdeğer İki Yarı Puanları Arasındaki Korelasyon ve Cronbach Alpha Katsayısı}

AA ölçeği için eşdeğer iki yarı puan korelasyonu bulunmuştur. Ölçek, "tek ve çift numaralı" soru tekniğiyle iki yarıya bölünmüştür. İki yarı korelasyon katsayısı 0.83 olarak hesaplanmıştır. Ayrıca, ölçeğin iç tutarlılık katsayılarına bakılmıştır. 738 öğrenci ve öğretim elemanlarının vermiş olduğu cevaplar üzerinde ölçeğin bütünü için Cronbach Alpha katsayısı hesaplanmış olup sonuç 0.901 bulunmuştur. Cronbach Alpha katsayısı kalite güvencesi alt temasında ( 7 madde) 0.795 ve kalite değerlendirmede (10 madde) 0.866 bulunmuştur.

\subsection{AMOS İe Doğrulayıcı Faktör Analizinin Yapılması}

AA ölçeğini geliştirirken AMOS programı yardımıyla doğrulayıcı faktör analizi yapılmıştır (Şekil 1). Doğrulayıcı faktör analizi (DFA), yapı geçerliği analizlerinde kullanılabilmektedir (Bollen, 2007, 41-44; Sümer, 2000, 49-50). "AMOS ile verinin, faktör analitik yapısının hipotez edilen modele nasıl uyduğu sınanır" (Bayram, 2010, 42). Bu tür araştırmalarda, modelin değerlendirme ölçütlerinin uygun olabilmesi, örneklem hacminin büyük ölçüde büyüklüğüne bağlıdır (Tezcan, 2008). AMOS programından elde edilen sonuçlar Şekil 1'de sunulmuştur. AMOS çıktısında kaykare değeri 238.872 bulunmuştur. Kay-kare (x2) / Serbestlik derecesi, 238.872 / $117<3$ olduğundan dolayı kabul edilebilir bir model uygunluğundan söz edilebilir. Modele ilişkin uyum iyiliği indisinin (GFI=0.963) 1'e yakın olması ve yaklaşık hataların ortalama karekökü (RMSEA $=0.038$ ) değerinin uygun olması bu uyumun desteklendiğini göstermektedir (AA Ölçeği Ek-1'de sunulmuştur). 


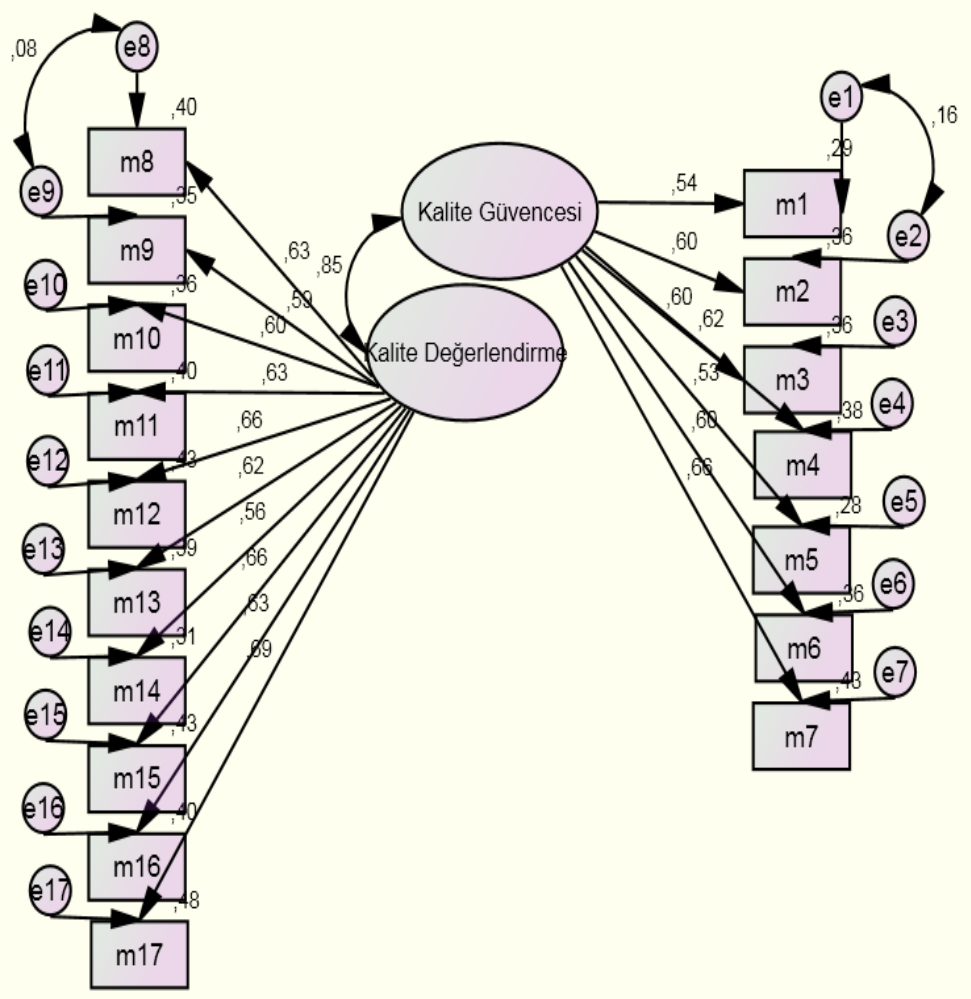

Şekil 1. Akreditasyon algısı ölçeğinin AMOS sonuçları

Şekil 1'de AA ölçeğinin doğrulayıcı faktör analizi sonuçları görülmektedir. Madde 1-17 (M1-M17) arası gözlenen değişkenler ve akreditasyon algısı ise gizil değişkendir. Şekilde, e1-e17 arası her bir gözlenen değişkenin ölçüm hatası görülmektedir. Şekilde verilen tek yönlü oklar, gizil değişkenden gözlenen değişkenlere doğru giden regresyon katsayılarıdır. Ölçeğin doğrulayıcı faktör analizi sonuçlarının uyum indeksleri ile karşılaştırılması Tablo 5'te verilmiştir. 
Tablo 5.

AA ölçeğinin doğrulayıc faktör analizi sonuçlarının uyum indeksleri ile karşılaştırılması

\begin{tabular}{|c|c|c|c|c|c|}
\hline $\begin{array}{l}\text { Model } \\
\text { uyum } \\
\text { indeksleri }\end{array}$ & AA Ölçeği & $\begin{array}{l}\text { İyi Uyum Standart } \\
\text { Ölçüleri (iUSÖ)* }\end{array}$ & $\begin{array}{l}\text { Kabul Edilebilir Uyum İyiliği } \\
\text { Standart Ölçüleri (KEUisÖ)* }\end{array}$ & $\begin{array}{l}\text { Karşılaştırma } \\
\text { iusö }\end{array}$ & $\begin{array}{l}\text { Karşılaştırma } \\
\text { KEUisÖ }\end{array}$ \\
\hline$x^{2 / s d}$ & 2.042 & $0 \leq \chi 2 / \mathrm{sd} \leq 2$ & $2 \leq \chi^{2} / \mathrm{sd} \leq 3$ & & + \\
\hline RMSEA & 0.038 & $0 \leq \mathrm{RMSEA} \leq 0.05$ & $0.05 \leq \mathrm{RMSEA} \leq 0.08$ & + & \\
\hline SRMR & 0.0312 & $0 \leq S R M R \leq 0.05$ & $0.05 \leq S R M R \leq 0.10$ & + & \\
\hline GFI & 0.963 & $0.95 \leq \mathrm{GFI} \leq 1.00$ & $0.90 \leq \mathrm{GFI} \leq 0.95$ & + & \\
\hline CFI & 0.969 & $0.97 \leq \mathrm{CFI} \leq 1.00$ & $0.95 \leq$ CFI $\leq 0.97$ & & + \\
\hline $\mathrm{NFI}$ & 0.942 & $0.95 \leq \mathrm{NFI} \leq 1.00$ & $0.90 \leq N F I \leq 0.95$ & & + \\
\hline
\end{tabular}

Tablo 5'teki bilgiler incelendiğinde, tahmini modelde, $\chi 2$ /sd (CMIN/DF) değeri 2.042 olarak hesaplandığı görülmektedir. Bu sonuç kabul edilebilir uyum iyiliği standart ölçülerine $(2 \leq x 2$ /sd $\leq 3)$ göre kabul edilebilir düzeydedir. Yaklaşık hataların ortalama kare kökü (RMSEA), 0.038 bulunmuştur. RMSEA, iyi uyum standart ölçülerine $(0 \leq R M S E A \leq 0.05)$ göre uygundur. $\mathrm{Bu}$ çalışmada, RMSEA'nın yaklaşık 0.04 çıkması, mükemmel bir uyumun olduğunu ve evren ile örneklem kovaryansları arasında bir farkın olmadığını göstermektedir. Diğer taraftan, "Standardize edilmiş kalıntıların ortalama karekökü (SRMR) değerinin sıfıra yakın olması kabul edilebilir bir uyumu gösterir" (Bayram, 2010, 72). Bu çalışmada, standardize edilmiş kalıntıların ortalama karekökü hesaplamasında iyi uyum standart ölçüsü olarak belirtilen durum gözlenmiştir (SRMR=0.0312). Uyum iyiliği indeksi (GFI) ile gözlenen değişkenler arasında kovaryans hesaplaması yapılmıştır. Ölçek çalışmasının GFI sonucu 0.963 olarak bulunmuş ve kabul edilebilir uyum standart ölçüleri arasında yer almıştır. Düzeltilmiş uyum iyiliği indeksi (AGFI), serbestlik derecesi dikkate alınarak hesaplanmış ve sonuç 0.951 bulunmuştur. Bu sonucun ideal iyi uyum standart ölçüleri içinde yer aldığı görülmüştür. Bu çalışmada normlandırılmış uyum indeksi (NFI) 0.942 bulunmuştur. Kabul edilebilir uyum iyiliği standart ölçülerine göre $(0.90 \leq \mathrm{NFI} \leq 0.95)$ uyum uygunluğu görülmektedir. Karşılaştırmalı uyum indeksi (CFI), 0.969 bulunmuş ve kabul edilebilir olduğu görülmektedir. Genel değerlendirmeye göre, modelin güçlü bir uyum içinde olduğu görülmektedir.

\section{SONUÇ VE TARTIŞMA}

Araştırmada, Akreditasyon Algısı (AA) Ölçeği geliştirilmiştir. Ölçek 738 öğrenci ve öğretim elemanlarına uygulanmıştır. Bu sayı taslak ölçekteki madde sayısının 9.84 katı, nihai ölçekteki madde sayısının 43.4 katı kadardır. Krejcie \& Morgan'a (1970) göre, AA ölçeğinin geliştirilmesinde uygulama yapılan kişi sayısı yeterlidir.

AA ölçeği için yapılan analiz sonuçlarına göre, ölçeğin kullanabilirlik için yeterli olduğu söylenebilir. Ölçeğin faktör yüklerinin 0.538-0.692 arasında ve madde toplam korelasyonlarının 0.55-0.68 arasında değiştiği görülmektedir. İki yarı puanları arasındaki korelasyon katsayısı 0.95 ve AA ölçeğinin Cronbach Alpha katsayısı 0.901'dir. Diğer taraftan, AMOS programı ile yapılan doğrulayıcı faktör analizi sonucunda ortaya çıkan uyum indeksi değerleri (Kay kare=238.872, $\mathrm{Sd}=117, \mathrm{X}^{2} / \mathrm{Sd}=2.042, \mathrm{GFI}=0.963, \mathrm{CFI}=0.969, \mathrm{RMSEA}=0.038$ ) ölçeğin geçerli bir yapıda olduğunu göstermektedir. Bu hesaplamalarda Kay-kare önemli bir değerdir. AA ölçeğinde bu değer 2.042 bulunmuş ve kabul edilebilir standart ölçü sınırları içerisinde görünmektedir.

Araştırma sonucuna göre AA ölçeği, üniversite (yükseköğretim) öğrenci ve öğretim elemanlarına uygulanabilir. Ölçek, büyük ölçüde eğitim fakültesi öğrencilerine ve düşük ölçüde öğretim elemanlarına uygulanmış olması bir sınırlılığını göstermektedir. Ayrıca, ilk ve ortaöğretim okulları için akreditasyon algısı ölçekleri geliştirilebilir. 


\section{KAYNAKLAR}

Akademik

İstatistik,

(2017).

Açımlayıcı/Keşfedici

Faktör

Analizi, http://akademikistatistik.com/acimlayici-kesfedici-faktor-analizi/ web adresinden 10.08.2017 tarihinde indirildi.

Ayvaz, B.; Kuşakçı, A.O. ve Borat, O. (2016). Kalite Güvencesi ve Akreditasyon Süreçleri. Yeni Türkiye, 88, 1-8.

Bakioğlu, A. ve Baltacı, R. (2017). Akreditasyon, eğitimde kalite, (2. Basım). Ankara: NOBEL Yayıncılık.

Bayram, N. (2010). Yapısal eşitlik modellemesine giriş: Amos uygulamaları, Bursa: Ezgi Kitapevi.

Bollen, K.A. (2007). An overview of structural equation models with latent variables, The Miami University Symposium on Computational Research, March 1-2. Miami University, Oxford, UK.

Büyüköztürk, Ş. (2002). Veri analizi el kitabı, Ankara: Pegem A Yayıncılık.

Büyüköztürk, Ş.; Çakmak, E.K.; Akgün, Ö.E.; Karadeniz, Ş. ve Demirel, F. (2009). Bilimsel araştırma yöntemleri, 3. Baskı, Ankara: Pegem Akademi.

Doğan, i. (1999). Eğitimde kalite ve akreditasyon sorunu: eğitim fakülteleri üzerinde bir deneme. Eğitim Yönetimi, 20, 503-519.

Erkuş, L. (2003). Eğitim fakültelerinin akreditasyon sürecine hazır olma durumlarına ilişkin öğretim elemanlarının görüşlerinin değerlendirilmesi, Yayımlanmamış Yüksek Lisans Tezi, Kırıkkale Üniversitesi, Kırıkkale

Herdman, E.A. (2010) Akretidasyon Süreci. (Çev. D. Sepit). Hemşirelikte Eğitim ve Araştırma Dergisi, 7 (2), 3-5.

Kaptan, S. (1998). Bilimsel araştırma ve istatistik teknikleri, Ankara: Tekışık Web Ofset Tesisleri.

Karasar, N. (1995). Bilimsel araştırma yöntemi, 7. Basım, Ankara: Alkım Yayınevi.

Krejcie,R.V. \& Morgan, D.W. (1970). Determining sample size for research activities. Educational and Psychological Measurement, (30), 607-610.

Sönmez, V. ve Alacapınar, F.G. (2011). Örneklendirilmiş bilimsel araştırma yöntemleri, Ankara: ANI Yayıncilık.

Sümer, N. (2000). Yapısal eşitlik modelleri: Temel kavramlar ve örnek uygulamalar. Türk Psikoloji Yazıları, 3(6), 49-74.

Tezcan, C. (2008). Yapısal eşitlik modelleri, Yayımlanmamış yüksek lisans tezi, Hacettepe Üniversitesi, Ankara.

Ünal, F.; Semerci, N. ve Semerci Ç. (2017). Öğretmen adaylarının programların akreditasyonuna ilişkin algıları. Uluslararası Öğretmen Eğitimi ve Akreditasyon Kongresi (19-21 Mayıs 2017), (EPDAD, Marmara ve Yıldız Teknik Üniversitesi İşbirliğiyle), istanbul.

YÖK, (2015). Yükseköğretim Kalite Güvencesi Yönetmeliği. Resmî Gazete, Sayı 29423, 23 Temmuz

2015. http://www.yok.gov.tr/documents/10279/16595796/yuksekogretim_kalite_guvencesi_ yonetmeligi_resmi_gazete+\%281\%29.pdf/4f97cac7-9ceb-4592-a3ba-3d9236ee7a36 web adresinden 28.07.2017 tarihinde indirildi 
Akreditasyon Algısı Ölçeği

Maddeler

1. Akreditasyon, ulusal ve uluslararası tanınmayı kolaylaştırır.

[ ]

2. Akreditasyon, bir eğitim programının kendini gerçekleştirmesidir.

[ ]

3. Akreditasyon, varolmanın tescillenmesidir.

4. Akreditasyon, belge veya rapor değildir, kaliteye kalite katma çabasıdır.

[ ]

5. Akreditasyon, bir programı yaşatma güvencesidir.

[ ]

6. Akreditasyon, programların geleceğinin güvence altına alınmasıdır.

[ ]

7. Akreditasyon, tercih edilen bir programın kalite güvencesidir.

[ ]

8. Akreditasyon, sürdürülebilir bir kalite göstergesidir.

9. Akreditasyon, kalite çizgisinin tabanıdır.

10. Akreditasyon, bir kalite kültürüdür.

11. Akreditasyon, algı, imaj ve kaliteyi olumlu yönde etkileyen bir faktördür.

12. Akreditasyon, eğitim kalitesinin bir göstergesidir.

[ ]

13. Akreditasyon, yaşam boyu kalite mücadelesi için atılan bir adımdır.

14. Akreditasyon ve kalite için tüm paydaşların hesap verebilir olması gerekir.

15. Akreditasyon, öğretim kalitesine olumlu yönde katkı sağlayan başarılı bir girişimdir.

16. Akreditasyon, kalite yönetiminin bir alt boyutu olarak değerlendirilebilir.

17. Akreditasyon, kaliteyi değerlendirmek için kullanılan bir araç ve yöntemdir. 


\section{SUMMARY}

\section{Development of Accreditation Perception (AP) Scale: Validity and Reliability Study}

Although accreditation is a Latin-based French concept (Doğan, 1999, 511), it was only known as a method that was unique of Americans until ten years ago (Fraser, 1994 as cited in Herdman, 2010, 3). However, it is apparent that today it has spread all over the World. Accreditation is a quality assurance process by which authority, competency and credibility are certified. (Herdman, 2010, 3). In this respect, accreditation and quality assurance are intertwined concepts. Quality Assurance can be described as "all planned and systematic processes to ensure that a higher education institution or program fully fulfills the quality and performance processes consistent with internal and external quality standards" (YÖK, 2015; Ayvaz, Kuşakçı ve Borat, 2016, 5). Accreditation is also a model covering quality assessment. According to the Council of Higher Education (YÖK) (2015), quality assessment is the evaluation and determination of the quality of education and training, research and administrative services of a higher education institution / department / program.

In the success of accreditation at universities in Turkey, the perceptions and thoughts of the instructors and also students are of great importance. However, it seems that the accreditation perceptions of the instructors are not very high. Only two-fifths $(2 / 5)$ of the instructors believe that the accreditation process will improve the quality of the faculties, and one-third (1/3) seems to be ready to be accredited (Erkuş, 2003, 3). That the concept of accreditation is not sufficiently adopted (Ünal, Semerci ve Semerci 2017; Erkuş, 2003, 3) may be thought as a reason stemming from the fact that this concept is not well known

This research aims to develop an Accreditation Perception (AP) scale. The survey model was used to develop the scale. In the framework of this model, current events and situations are examined (Kaptan, 1998, 59; Büyüköztürk et al., 2009, 16-17; Karasar, 1995, 77; Sönmez \& Alacapınar, 2011). The "accreditation perception" scale was reduced to 75 items from a pool of 81 of items by expert opinions and designated as one and multi-dimensional scale in 738 sample groups. The application of the scale was mainly conducted at the university in the western black sea region in Turkey. In the development of the AP scale, the following steps have been taken:

1. The Accreditation Perception Scale, ranging from "Completely (Totally) agree (5), Mostly agree (4), Partially agree (3), Slightly agree (2), Don't agree at all (Disagree) (1)", was composed of 81 items as a result of reviewing the literature and investigations, and placed in the pool as 75 items in the direction of expert opinions.

2. For confirming the content validity of the AP scale, three experts, two (2) assistant professors and one (1) professor working in the Education Faculties of two different universities and dealing with accreditation issues, were consulted. Additionally, eight (8) master's degree students and two (2) doctoral students were asked about the clarity of the related items. In the direction of expert and student opinions, only minor spelling corrections were made on the items. The draft scale consisted of 75 items. These items determined in line with expert opinions were applied to 738 students and instructors and the data were processed.

3. Factor analysis was performed for the 75 items created in the pool. Factor analysis is a multivariate statistics that "aims to discover a small number of unrelated and conceptually meaningful new dimensions by bringing the $p$ associated variables together " (Büyüköztürk, $2002,117)$. In the study, the items with factor loadings less than 0.50 were removed from the scale. The scale can be used as a one-dimensional and a multi-dimensional scale. The factor loads of the scale items range from 0.538 to 0.692 . As a result of the factor analysis, an explained variance for $43.357 \%$ of the scale was provided. The KMO value of the AP scale was 0.964 and the Bartlett test was 6.045E3 $(\mathrm{Df}=253, \mathrm{p}=0.000)$. Item total correlations of the AP Scale were calculated and found to range from 0.55 to 0.68 . Büyüköztürk $(2002,32)$, emphasizes that item total correlations should be 0.30 and above.

4. Sub- themes of the scale are "quality assurance" and "quality assessment". There are 17 items on the scale, including 7 items for "quality assurance" and 10 items for "quality assessment". 
When the correlations between the sub-themes of the AP Scale were examined, there was a 0.703 relationship between quality assurance and quality assessment dimensions.

5. For the AP scale, the correlation of two equivalent forms was used. The items on the scale were split into halves, based on odd and even numbered items in reliability analysis. The two half correlation coefficients were calculated as 0.83 . Additionally, the internal consistency coefficients of the scale were examined. The Cronbach Alpha coefficient was calculated for the whole scale on the answers given by 738 students and instructors and the result was found to be 0.90 . The Cronbach Alpha coefficient for the "quality assurance" sub-theme ( 7 items) was 0.795 and for the "quality assessment" sub-theme (10 items) was 0.866 . Although the lowest reliability coefficient was found for the "quality assurance" sub-theme due to having a small number of items, it was decided by the researcher that it could be accepted.

6. The validity and reliability value of the AP scale were provided through the confirmatory factor analysis with AMOS program (Chi-square=238.872, Df=117, $\mathrm{X}^{2} / \mathrm{Sd}=2.042, \mathrm{GFI}=0.963, \mathrm{CFI}=0.969$, RMSEA=0.038).

In line with the results of this research, it is suggested that the AP scale can be applied to university students and instructors. In addition, similar sclaes should be developed for k12 education. 